\title{
Conceptualising ‘Communication’ in Second Language Acquisition
}

\begin{abstract}
Overviewing how the field of Second Language Acquisition (SLA) conceptualises 'communication' is a complex task. First, researchers differ in their interpretations of the nature of the object of inquiry and the goals of their research, based on different philosophical assumptions about the nature of language and the processes involved in language learning. Second, the meaning of the concept 'communication' is generally taken as widely understood and is seldom defined. This paper uses the definitions of SLA in three paradigms within the field to explore how these paradigms conceptualise 'communication' and its role in the development of the second language linguistic system.
\end{abstract}

\section{Key words}

Communication, interaction, conversation, second language acquisition

\section{Introduction}

Reviewing how the field of Second Language Acquisition (SLA) conceptualises 'communication' is complicated by ambiguity and diverse perspectives. First, and despite the centrality one would expect of this concept in such a field, there are few definitions of what researchers working in this area understand by 'communication'. The Cambridge Encyclopaedia of Language (Crystal 1987), for instance, includes 10 entries for 'communication' and related issues in the index of topics, but the term is not defined in the text or the glossary. A similar situation obtains in other reference books and Applied Linguistics dictionaries. 'Communication' is generally assumed to be commonly understood.

A second factor that complicates the issue is "the very nature of the SLA beast" (Long 1997: 207). SLA is a multidisciplinary field, drawing from a number of scholarly areas such as linguistics, psycholinguistics and cognitive psychology, sociology, anthropology and education. The plurality of sources informing this field may stem from the multifaceted nature of language acquisition, which involves socio- and psycholinguistic factors as variables (Regan 1998). Acknowledging its complexity, Ellis characterised SLA research as "a rather amorphous field of study with elastic boundaries" (1994: 2). Scholars disagree on how far the boundaries extend, and thus on how to define the scope, nature and research aims of inquiries within the field. ${ }^{1}$ Compounding this lack of clarity is the position of SLA at the interface between theory and practice (Kramsch 2000: 318) and the problem, still debated, of the relationship between SLA, Applied Linguistics and second/foreign language teaching pedagogy.

Ellis (1997, cover blurb) defined second language acquisition as "the study of the way in which people learn a language other than their mother tongue". Even this simple definition, as Seidlhofer (2003) noted, is problematic. She identified a number of issues that are open to debate, namely, "that 'SLA' stands for the 'study of SLA'; that 'second language' includes such notions as 'foreign language' and 'third, fourth, ...nth language'; that the 'A' in SLA covers both 'acquisition' and 'learning' [...];

\footnotetext{
${ }^{1}$ The lively discussions that followed the publication of Firth and Wagner's (1997) position paper on the boundaries of SLA provide an excellent repertoire of views that characterise the field.
} 
lastly, 'learning' refers to different kinds of learning (for example, inside a classroom or by living in the country where the target language is spoken" (p.169). Over the years, sociocultural perspectives have developed to replace and/or supplement linguistic approaches to SLA. These have generated further points of contention and further debates about the role of the native speaker as the benchmark for ultimate linguistic attainment, the impact of language on the construction of identity, native versus non-native speaker norms, standard versus non-standard varieties and so forth (see Kramsch 1997, Paikeday 1985; Cook 1999).

Given the heterogeneity of perspectives summarised briefly here, it is scarcely surprising that the field of SLA does not uphold a singular or even uniform view on the concept of 'communication' and its role in the process of acquiring a second language. In exploring the different conceptualisations of communication that characterise the field, it is therefore important to begin by elucidating the diverse perspectives on what SLA as a field of inquiry involves. Kramsch (2000) provided a useful starting point towards this aim. An informal survey she conducted to deepen understanding of how US university academics and administrators conceptualise the field of SLA yielded what she identified as three types of definitions based on the respondent's perceived scope of the discipline. These definitions ranged from "a phenomenon that is purely internal to the learner, to an interaction between the learner and an educational context, to the individual and societal aspects of multilingualism" (2000: 314). In this paper I use these three broad definitions as a framework to explore the different perspectives on 'communication' that can be found in the field of SLA. These three definitions ultimately reflect diverse philosophical assumptions about the nature of language and the processes involved in language learning.

\section{Definition 1: Psycholinguistic perspective}

Psycholinguistic perspectives on SLA do not represent a single and unified system but include a number of approaches that embody diverse goals and analyses. Common to all the strands within this paradigm, however, is a focus on mental processes that drive language development, and the recognition of cognitive variables as the central focus of inquiry. The primary aim of SLA is to build a theory of how mental representations of second language linguistic systems, or interlanguages (Corder 1967), develop within individual minds or brains, to describe how changes in linguistic competence are achieved, to explain why acquisition sometimes seem to cease, and to examine aspects that may influence the process. Thus Gass defined her primary research interest as the "determination of the linguistic systems of learners (sometimes known as non-native speakers) and the determination of how that knowledge evolves. In short, the central question [of SLA] relates to how non-primary acquisition takes place” (1998: 84).

Second language acquisition is thus seen as "a phenomenon of the individual" (Corder 1973: 24), internally driven, and "largely independent of the context in which it takes place” (Kramsch 2000: 314). VanPatten thus claims, “...Many of the questions [SLA investigates] ignore any classroom-versus-non classroom distinction in that the internally driven development of a second language does not change with context" (1999: 49-50).

The focus on the individual does not imply that adherents to this tradition completely disregard sociolinguistic aspects. They recognise explicitly that second language is 
acquired in a social context, and that the surrounding environment can play a role in promoting or hindering development of a second language system (Gebhard 1999). As I discuss shortly, researchers also acknowledge that second language is acquired crucially through participating in conversations. Yet, the object of inquiry is the development of the learner's internal linguistic representations, as the impact of other factors is considered to be of minimal importance (see Gass, 1998; Kasper, 1997).

With regard to 'communication' and its role, two positions can be discerned in this perspective. Most research conducted within the generative tradition has typically been unconcerned with the issue of communication; here the main focus of inquiry has been on internal, mental processes. Communication is seen to contribute little to language acquisition, except, perhaps, as a source of linguistic input. Thus Krashen (1985), who developed one of the most widely followed second/foreign language teaching methodologies, argued that the necessary and sufficient condition for language acquisition is the exposure to 'comprehensible input'. ${ }^{2}$ This view claims that in a developmental process parallel to first language acquisition, the mind extracts structure and develops a grammatical system without any need to produce language or interact with others. Swain (1993) challenged this view with her focus on the role of 'comprehensible output', suggesting that "Learners need to be pushed to make use of their recourses; they need to have their linguistic abilities stretched to their fullest; they need to reflect on their output and consider ways of modifying it to enhance comprehensibility, appropriateness, and accuracy" (1993: 160-161). Unlike comprehension, through which learners can interpret messages without recourse to knowledge of the target language syntax, forced production pushes learners to impose syntactic structure on their utterances, thus stimulating the development of their interlanguage.

The citation above points to a second position on communication within the research on interaction. ${ }^{3}$ Here communication is seen not merely as a source of linguistic input but also as a tool to facilitate language acquisition. Hatch (1978), in one of the earliest works to consider how conversations could contribute to second language development, proposed that it is through social interaction with interlocutors that learners process target language messages as input for learning. Long has cast this as the Interaction Hypothesis, noting "Negotiation for meaning, and specially negotiation work that triggers interactional adjustments by the NS [native speaker] or more competent interlocutor, facilitates acquisition because it connects input, internal learner capacities, particularly selective attention, and output in productive ways" (Long 1996: 451-452). ${ }^{4}$

Similarly, Gass and Mackey describe the role that interaction plays in acquisition, proposing that, "through input and interaction with interlocutors, language learners have opportunities to notice differences between their own formulations of the target language and the language of their conversational partners. ${ }^{5}$ They also receive

\footnotetext{
2 'Comprehensible input' is defined as input that is a little beyond the learner's present "level”. Krashen defined the present "level" as $i$ and the ideal level of input as $i+1$.

3 The terms 'interaction' and 'communication' seem to be used as synonyms in this literature.

${ }^{4}$ A thorough discussion of this approach can be found in Long (1980), Varonis and Gass (1985), Pica (1998) and Gass and Mackey (2006).

${ }^{5}$ Note that Long (1980) argued for the need for interaction for language learning. He did not specify that interaction needs to be conducted with native speakers. Varonis and Gass (1985) argued that -
} 
feedback which both modifies the linguistic input they receive and pushes them to modify their output during conversation" (2006: 3). In this view three elements are involved in the development of linguistic competence: exposure to the target language (input), pressure to communicate (output) and feedback on production.

Research in this tradition focuses on the relationship between communication and language acquisition and tries to unveil the cognitive mechanisms (e.g., noticing, selective attention, scaffolding) that mediate between these processes and shape the learner's developing linguistic system (Gass 2003). These operate more usefully during negotiation for meaning, defined as "the process in which, in an effort to communicate, learners and competent speakers provide and interpret signals of their own and their interlocutor's perceived comprehension, thus provoking adjustments to linguistic form, conversational structure, message content, or all three, until an acceptable level of understanding is achieved” (Long 1996: 418). Learners also receive negative feedback that may facilitate acquisition, at least in the areas of vocabulary, morphology and syntax. de Bot, Lowie and Verspoor (2005) thus suggest that interaction should be considered as facilitating rather than causing SLA, as the sources of learning are complex and can be seen as stemming mostly from learnerinternal factors.

To sum up, research from the interactionalist perspective views contextual factors as playing a major role in shaping the learner's developing language system. This runs counter to traditional pedagogical practices, still prevalent in language classrooms, in which 'communication' serves either as a way of reinforcing the lexicon and grammatical structures and rules students need to master, or, at advanced levels, as something learners can engage in once the basic target grammar are in place (the 'icing on the cake’ approach).

Despite recognition that interactions play an important role in language acquisition, this role appears to be purely instrumental, as interactions are considered valuable insofar as they bring about interlanguage change, thus enhancing the developing second language linguistic system. There is little, if any, interest in interactions as social processes that impact on individual dimensions other than the cognitive, or on the social, cultural or educational contexts in which interactions take place.

This point is emphasised strongly in the literature. Gass (1998), for instance, argued, "The research question central to SLA that I and others ask is: How do people learn a L2? -The question is not: How do people use a L2, unless the latter question is a means of getting at the former" (1998: 85). ${ }^{6}$ Long goes even further in denying the need to focus on aspects other than the cognitive, claiming poignantly that "SLA is a process that (often) takes place in a social setting, of course, but then so do most internal processes - learning, thinking, remembering, sexual arousal, and digestion, for example - and that neither obviates the need for theories of those processes, nor shifts the goal of inquiry to a theory of the settings" (1997: 207). Here a clear

non-native speaker-non-native speaker interactions might have greater benefit for learners that native speaker-non-native speaker interactions.

${ }^{6}$ Similarly, Poulisse argued, "You first need to describe the basic processes of learning and using language, and then discuss the contextual factors that may influence these processes" (1997: 324) 1997: 324). 
distinction is made between the linguistic system being acquired and its use in communication.

Critics of this perspective argue that the view of language underpinning research in this tradition is too restricted. For these critics, language is not primarily a formal, standardised system as this perspective assumes, but a social and cultural practice (Kramsch 1997). Brumfit (1997: 22), for instance, argued that "Language [...] is instantiated in social and psychological behaviour and consequently autonomous descriptions are inefficient [...] because they are partial”.

The view of communication embedded in this perspective has also been criticised as being too restricted, as it seems to focus exclusively on oral-aural modes of interaction. Savignon, one of the first theorists to apply Hymes' concept of communicative competence to language learning, defined communication as "a negotiation of meaning between speaker and hearer, author and reader” (1987: 236). Communication thus extends to interaction between learners and written texts. The emphasis that researchers on interaction place on the feedback, however, suggests that oral communication is the main skill targeted.

A further limitation of this paradigm is an assumption that 'communication' involves simply transferring a message, as if the learner has a preverbalised notion of what they want to convey and simply has to find the right words and structures to do so. Breakdowns in communication therefore stem from the (as yet) underdeveloped linguistic system, a perspective substantially different from the one I explore in the next section. A final limitation in this paradigm is the failure to take account of nonverbal aspects of communication such as paralanguage, gestures, body postures, time and space that researchers identified as crucial to the communication process (see Guerrero, DeVito and Hecht 1999, Mehrabian 1971).

The view of the learner underpinning this perspective has also drawn considerable criticism for its limitations (see, for instance, Firth and Wagner 1997). In particular, critics view its focus on the learner as an acquirer of a formalistic, context free 'linguistic competence' as insufficient to account for the complex nature of language acquisition. Critics propose expanding the focus of SLA studies beyond the processes involved in understanding and producing grammatically accurate utterances to include language use and the interactional and sociolinguistic factors that enable learners to communicate in contextually appropriate ways (see, for instance, Canale and Swain 1980; Hymes 1971). This perspective is embedded in the second definition, to which we now turn.

\section{Second definition: Focus on language use}

Calls to broaden the field of SLA find expression in the second definition I discuss here, which Kramsch (2000: 314) has identified. As well as traditional research on psycholinguistic factors that influence second/foreign language acquisition, it includes "applied SLA research" that explores the nature of the learning environment and its role in facilitating or hindering linguistic development. This definition establishes firmly the strong links between SLA research and second/foreign language pedagogy, a field that "inquires about the social, psychological, cognitive and institutional dimensions of language instruction" (Kramsch 2000: 315). From this perspective, understanding the interaction between the learner and the educational context 
(involving learners, other speakers, and institutional practices) is a primary goal of SLA research.

As Kramsch suggests, this definition seems to align itself with sociocultural approaches to SLA, which include a wide range of theories and proposals (e.g., Hall 1993; Lantolf 1994; Vygotsky 1962). Despite their differences, researchers in this tradition share Hymes' conceptualisation of language first and foremost as "a social and cultural phenomenon" (1971: 287), that is "acquired and used interactively, in a variety of contexts for myriad practical purposes" (Firth and Wagner 1997: 296). Thus language use rather than structure becomes a crucial object of inquiry.

Another point of agreement among researchers is the view of language learning as socially constructed and constituted through interactions in situated activities. As evident from our discussion in the previous section, interactions are also of great interest to the psycholinguistic tradition. Nevertheless, the perspectives of these two paradigms differ radically from each other. While most research in interaction views conversations as loci to stimulate and explore intra-individual cognitive processes, sociocultural research focuses on the inter-individual dimensions of second language learning (Kasper 2006). This research inverts the process of language acquisition. Its analytical starting point is the learner as a social and cultural being who first experiences communication as social processes and practices, and internalises the linguistic system of the target language only later and as an individual, cognitive phenomenon (Kramsch 2000). Psycholinguistic aspects of SLA are clearly important here, but cognitive structures are seen to be influenced and developed through social engagement (Firth and Wagner 1998). Since cognition is rooted in the daily social and cultural practices of the communities in which individuals participate as active agents (Gebhard 1999), the emphasis shifts from the product of interaction to the social and cultural contexts of interaction and exploring how these impinge on the learner. Learners are thus seen as active and creative agents in a socio-cognitively complex task (Hall 1997). Thus Gass and Varonis (1985: 150) contend that "active involvement is a necessary aspect of acquisition, since it is through involvement that the input becomes 'charged' and penetrates 'deeply'”. Linguistic development in this approach can be understood only within communicative practices. ${ }^{7}$

The classroom as a context of interaction therefore acquires great importance in this paradigm since for most learners it is the primary site of language development (cf. VanPatten 1999). Hall, for instance, considers SLA “a theory of classroom practice”, arguing, "It is in the communicative practices of these classrooms that teachers and students together develop particular understandings of what constitutes language and language learning” (Hall 1997: 304). The teacher's role is seen as particularly consequential since this view assumes that participation opportunities that teachers make available to learners impact on the development of communities of language learners which in turn affects individual learners.

The conceptualisation of 'communication' is radically reconfigured in this paradigm. In mainstream psycholinguistic views, communication is seen as relevant insofar as it helps develop a cognitive system. The underlying idea is that once the learner

\footnotetext{
${ }^{7}$ Firth and Wagner (1998) conclude that these assumptions render the notion of competence - as opposed to performance - obsolete, as the one cannot be separated unproblematically from the other.
} 
develops the target language skills in a piecemeal fashion, s/he will be able to transfer this linguistic knowledge into new contexts (as language is context free) and will eventually become socialised into the target language community of speakers (Hall 1997). The product of communication is thus considered more important than the process. Moreover, 'communication' is seen primarily as a process of transferring ideas, messages or thoughts from a speaker to a listener, as if the speaker had a preverbalised message or goal that existed a priori of the interaction, converted it into a plan by selecting an appropriate communicative strategy, and then executed this transferral strategy through speech. Thus, meaning and interaction are seen as essentially two separate and discrete entities (Firth and Wagner 1997: 289).

Sociocultural perspectives invert this view. Rather than conceptualising language and its use as discrete, autonomous constructs that can be studied in isolation of one another, they view language as communication. Thus Firth and Wagner (1997) propose an emic (i.e., participant-relevant) perspective in which participants conjointly accomplish meaningful communication with the resources at their disposal. Meaning in this paradigm is seen not as something independent that exists in individual brains; it is a social product of interaction that transcends individual intentions and behaviours and is negotiated and co-created by the participants in the communication process through active engagement in conversations. As Firth and Wagner (1997) note, 'negotiation' does not mean that the interlocutors talk openly and explicitly to reach a kind of definite agreement on the meaning of a word or utterance. Normally, such negotiations are done implicitly and the interlocutor will show acceptance or understanding by producing the appropriate response (p. 297). Turn taking is the "procedural infrastructure" (Schegloff 1992: 1338) that provides participants with a most effective way to accomplish, demonstrate and transform meaning in an ongoing and incremental fashion. Each speaking turn, then, is a locus for displaying understanding of the prior turn (Schegloff 1992: 1300-1301; Firth and Wagner 1997: 291). ${ }^{8}$

Given these assumptions, breakdowns in communication are seen as problems that participants experience in interaction. Thus Firth and Wagner propose that "it may be more useful to view problems in communication as contingent social phenomena, as intersubjective entities, and not invariable as 'things' possessed by individuals" (1997: 291) who are perceived as being deficient communicators.

Sociocultural approaches view communication as always socially located within specific contexts of interaction so that language and context are inextricably linked. The contexts are both indexical, that is, created by the talk itself, and reflexive that is, in turn they create the talk (Heritage, 1984, in Liddicoat 1997: 313). Thus Liddicoat (1997) has criticised traditional research on interaction for isolating tokens of language from the linguistic and nonlinguistic contexts in which they occur. He argues that, in a view of language as communication, "sentences and utterances come to be seen not as isolated, self-contained artifacts of language, but rather as linguistic and social actions within a specific context and designed with that context in mind". Developing communicative competence in a second language involves far more than

\footnotetext{
${ }^{8} 8$ In his response to Firth and Wagner (1997), Long (1997) expresses scepticism as to whether greater insights into second language use will necessarily have much to say about second language acquisition. Similarly, Gass (1998) makes the point that some aspects of our knowledge of language, such as grammaticality, cannot arise from social interaction.
} 
learning the grammatical structures and rules of a target language; it involves acquiring the diverse linguistic tools and resources upon which cultural practices are rooted. These means for communication include, among other things, "the rhetorical scripts that lay out the typical trajectories of speech acts, the patterned ways in which turns are taken, and the linguistic and other interactional means by which typical opening, transitional, and closing turns are accomplished” (Hall 1997: 303). Acquiring a language is thus equated with internalizing conversational conventions.

Given the centrality that the language classroom assumes in this paradigm, it is fitting to question whether (and how?) this classroom can be used to provide learners with the opportunities to engage in the types of social interactions needed to develop communicative competence through engagement and contextualisation (de Bot et al., 2005: 83). Few researchers believe this is possible (Seedhouse 1996).

Reasons for this impossibility relate to the artificiality of most classroom activities and the language produced in them, and the quantity of input to which learners are exposed. Unlike 'authentic communication', which occurs "in a variety of contexts for myriad practical purposes" (Firth and Wagner 1997: 296), language produced in the classroom typically has some pedagogical aim, either to expose learners to, or prompt them to produce, language samples. Classroom interactions are examples of what Nunan (1987: 17) labels the 'IRF cycle' (i.e., teacher initiation-learner responseteacher follow-up). They are also characterised by display questions, rather than referential questions that usually characterise interactions between adult speakers. Classroom dialogues (scripted and semi-scripted) are produced similarly, to illustrate or practice some specific grammar rules, and bear little similarity with authentic conversations in which interactions are characterised by speaker-listener control of the topic, the structures used and the flow of the conversation (Liddicoat 1997). Teachers control these dialogues even in selecting and pairing interlocutors. Moreover, and despite the stated focus on meaning found in most language classrooms nowadays, most classroom activities reveal a strong focus on grammatical structures as the basis of selecting and sequencing the materials. ${ }^{9}$ As an example, VanPatten, in a paper that aims at enhancing classroom communication, recommends anticipating students' capabilities and structuring the classroom by 'hierarchical ordering', which involves "sequencing of questions from yes/no type questions [...] through alternative questions [...] to finally arrive at more open-ended questions" (1982: 405). In real life interactions this hierarchical ordering of conversational turns would be unthinkable. Lastly, the quantity of linguistic input to which students are exposed may play a significant role. Duff and Polio (1990), in one of the few studies focussing on this issue, sampled 13 university level classes teaching a variety of languages. They found that the amount of target language input ranged from 100 percent in the highest case to 10 percent in the lowest. This may clearly be insufficient to promote acquisition and stimulate interaction. ${ }^{10}$

\footnotetext{
${ }^{9}$ This focus [would be? is? more consistent with the psycholinguistic paradigm which, ironically, is not concerned with classroom instruction.

${ }^{10}$ Some programs tried to remedy these limitations and create opportunities outside the classroom for further interaction (Eisenchlas and Hortiguera 1999; Montgomery and Eisenstein 1985). The organisation of these programs is too complex and therefore tends to be restricted to courses with small student intakes.
} 
Features of 'authentic conversations' and of classroom interaction show that these phenomena differ from each other. Warren (1993: 8, cited in Seedhouse 1996: 16) defined a conversation as "[a] speech event outside of an institutionalized setting involving at least two participants who share responsibility for the progress and outcome of an impromptu and unmarked verbal encounter consisting of more than a ritualized exchange". This definition automatically sets classroom interactions aside from 'natural conversations'. Furthermore, Drew and Heritage (1992: 19) see conversations as "a kind of benchmark against which other more formal or 'institutional' types of interaction are recognized and experienced. Explicit within this perspective is the view that other institutional forms of interaction will show systematic variations and restrictions on activities and their design relative to ordinary conversation". Classroom communication can thus be seen as an institutional phenomenon shaped by cultures and structures at work in educational systems (Gebhard 1999: 545). Similarly, Liddicoat (1997) considers classroom talk as a form of institutional talk, in which the roles of the participants in the interaction are both defined and constrained by the task, the context and the relationships between interlocutors.

There is no implication in the above to suggest that classroom interaction is inferior or deficient in comparison to 'authentic' communication. The view that there is something like 'authentic' or 'genuine' communication is one of the assumptions of the communicative orthodoxy concerning second language teaching (Seedhouse 1996), and suggests the idea that some kind of 'pure' communication exists independently of a context. Yet the above does imply that the development of 'communicative competence' as defined by Hall above may be too ambitious a goal for the language classroom to achieve.

\section{Third definition: Individual and societal multilingualism}

The third definition identified by Kramsch (2000) extends beyond the educational environment into the wider community. It aims to explain, in addition to basic and applied SLA phenomena, the role of language and language learning in multilingual and multicultural societies. This definition encompasses many areas of the general field of applied linguistics, defined by Brumfit (1991: 46) as "[t]he theoretical and empirical investigation of real-world problems in which language is a central issue”. These areas include insights from a number of theories (e.g., feminist theory, discourse theory, critical discourse analysis, intercultural communication, pragmatics) that examine how speakers position themselves vis-à-vis other speakers, and how they come to participate as members in the activities of another community of practice (Kramsch 2000).

Within this paradigm, a number of issues become relevant when looking at SLA. Learning a second language involves the possibility - or choice - of becoming socialised into particular speech communities in terms that go beyond acquiring interactional competence as defined by the sociocultural paradigm. Issues of power in society, and individual and group identity, play a significant role in this process; both affect the interactions between the diverse communities to which an individual may belong and are in turn affected by them. Similarly, face and power determine the choice of linguistic structures and resources and impinge on how individuals choose to project themselves. On a more global dimension, researchers in this tradition have focused on how power creates and reflects both the social structures and political 
ideologies that influence representations of individuals and groups. ${ }^{11}$ Another area of interest in this paradigm is how institutional power determines what - and how language is taught in classes. Other topics that have received great attention involve the linguistic norms to which learners are exposed, such as the relationships between standard and non-standard linguistic varieties, the role of the native speaker as an arbiter of grammaticality, and the concept of the 'learner' itself, which some researchers have challenged as inherently essentialist (Paikeday 1985).

This conceptualisation of SLA has drawn great opposition from researchers working within the boundaries of the traditional paradigms. They consider the inclusion of such varied approaches as an unwarranted extension of SLA that can only detract from the main goal of the discipline, i.e., understanding how a second/foreign language is acquired. Thus Kasper (1997: 310) argues, "If the 'A' of 'SLA' is dropped, we are looking at a much wider field of second language studies, which spans as diverse endeavours as intercultural and cross-cultural second language pedagogy, micro- and macro sociolinguistics with reference to second languages and dialects, societal and individual multilingualism, and SLA”. She further contends that none of these approaches has anything to say about second language learning.

It is probably in this wider characterisation of SLA - or Applied Linguistics - that studies of communication can be better placed in a way that avoids the limitations of both psycholinguistic approaches to SLA and sociocultural perspectives on classroom interaction. But as I mentioned above, many would argue that this broad definition of communication is beyond the scope of inquiry in SLA studies proper, and it 'trespasses' into other areas of linguistics (e.g., pragmatics, conversation analysis) that have their own particular goals and agendas. Views on communication within these theoretical frameworks are explored more fully elsewhere in this volume.

\section{Conclusion}

This paper has presented an overview of the field of SLA and a discussion of how the field conceptualises communication through examination of three particular broadly defined paradigms. It has shown that, due to the multidisciplinary nature of SLA, the boundaries of the discipline are still deeply contested. I have used definitions from each of the three paradigms to frame the discussion, expanding from an individual perspective and focus on language structure, to a social perspective that examined the role of language use on acquisition - mainly in the classroom, to a perspective that focuses on language and the role it plays in the wider community.

The concept of communication embedded in these approaches follows a similar trend of expansion. In psycholinguistic research, the limited interest in communication, seen as interaction, became the loci to explore individual cognitive processes; in the sociocultural perspective, communication is what first socialises learners into speech communities (particularly, the classroom), which in turn stimulates the development of the target language linguistic system. Finally, from the wider perspective of SLA conceptualised as Applied Linguistics, communication is seen as an arena for positioning the speaker vis-à-vis the wider community.

\footnotetext{
${ }^{11}$ See Devos (2003) and Clyne (2005) for interesting discussions.
} 
Despite the different roles attributed to language in the three paradigms, these three share some common threads in their understanding of how SLA conceptualises communication. One is the almost exclusive preoccupation on spoken discourse. The engagement with written texts, which could provide learners with linguistic input and stimulate negotiation for meaning, seems to be relegated in the literature to the area of pedagogy, although this may change after further research is conducted on chat and other means of synchronous interaction. A second trend is the focus on verbal communication and a disregard of nonverbal factors that play a role in interaction. Although researchers may mention the importance of these factors, studies in nonverbal communication have been conducted mostly in other academic disciplines (such as anthropology or psychology) and very few studies examine the role of these elements in the process of linguistic development.

The discussion here makes it clear that there is significant overlap in the topics considered. This is hardly surprising given that the boundaries of SLA as a discipline are still being contested. Yet I contend that this plurality of approaches needs to be welcomed rather than deplored, particularly in light of the multidimensional nature of the object of inquiry. In this spirit Gebhard has claimed that "use and acquisition are two faces of the same process; artificially pulling them apart therefore does not strike me as helpful" (1999: 550). Similarly, Gass (1998: 88) concluded, "Views of language that consider language as a social phenomenon and views of language that consider language to reside in the individual do not necessarily have to be incompatible. It may be the case that some parts of language are constructed socially, but that does not necessarily mean that we cannot investigate language as an abstract entity that resides in the individual”. On the other hand, as Firth and Wagner (1998) make clear, language acquisition will not occur without language use. The SLA field will surely benefit from a fuller understanding of how these two proposals may relate, and how communication mediates between the system and its use. The diversity of perspectives that currently marks the field provides a rich base for this exploration.

\section{References}

Brumfit C 1991 'Applied linguistics in higher education: Riding the storm' $B A A L$ Newsletter 38: 45-49.

Brumfit C 1997 'Theoretical practice: Applied linguistics and pure and practical science' AILA Review 12 1995/6:18-30.

Canale M \& M Swain 1980 'Theoretical bases of communicative approaches to second language teaching and testing' Applied Linguistics 1:1-47.

Clyne M 2005 'The use of exclusionary language to manipulate opinion: John Howard asylum seekers and the reemergence of political incorrectness in Australia' Journal of Language and Politics 4(2):73-96.

Cook V 1999 'Going beyond the native speaker in language teaching' TESOL Quarterly 33 (2):185-209.

Corder SP 1973 Introducing Applied Linguistics Harmondsworth England: Penguin. 
de Bot K, W Lowie \& M Verspoor 2005 Second Language Acquisition: An Advanced Resource Book New York: Routledge.

Devos A 2003 'Academic standards internationalization and the discursive construction of the international student' Higher Education Research and Development 22 (2):155-166.

Drew P \& J Heritage (eds) 1992 Talk at Work: Interaction in Institutional Settings Cambridge: Cambridge University Press.

Duff PA \& CG Polio 1990 'How much foreign language is there in the foreign language classroom' The Modern Language Journal 74 (2):154-166.

Eisenchlas SA \& H Hortiguera 1999 'Beyond the classroom: The Hispanic community as a resource for teaching and learning' Babel 34 (3):16-20.

Ellis R 1994 The Study of Second Language Acquisition Oxford: Oxford University Press.

Firth A \& J Wagner 1997 'On discourse communication and (some) fundamental concepts in SLA research' The Modern Language Journal 81 (3):285-300.

Firth A \& J Wagner 1998 'SLA property: No trespassing!' The Modern Language Journal 28 (1):91-94.

Gass SM \& A Mackey 2006 'Input interaction and output: An overview' AILA Review 19:3-17.

Gass SM 1998 'Apples and oranges: Or why apples and not orange and don't need to be a response to Firth and Wagner' The Modern Language Journal 81 (3):83-90. Gass SM 2003 'Input and interaction' in CJ Doughty \& MH Long (eds) The Handbook of Second Language Acquisition Oxford UK; Cambridge Mass: Blackwell publishing. Pp. 224-255.

Gass SM \& EM Varonis 1985 'Task variation and nonnative/nonnative negotiation of meaning' in SM Gass \& CG Madden (eds) Input in Second Language Acquisition Rowley MA: Newbury House. Pp.149-161.

Gebhard M 1999 'Debates in SLA studies: Redifining classroom SLA as an institutional phenomenon' TESOL Quarterly 33(3):544-557.

Guerrero LK, JA DeVito \& ML Hecht (eds) 1999 The Nonverbal Communication Reader 2nd ed Lone Grove Illinois: Waveland Press.

Hall JK 1993 'The role of oral practices in the accomplishment of our everyday lives: The sociocultural dimension of interaction with implications for the learning of another language' Applied Linguistics 14 (2):145-166.

Hall JK 1997 'A consideration of SLA as a theory of practice: A response to Firth \& Wagner' The Modern Language Journal 81 (3):301-306. 
Hatch E 1978 'Acquisition of syntax in a second language' in J Richards (ed.) Understanding Second and Foreign Language Learning Rowley MA: Newbury House.

Hymes D 1971 'Competence and performance in linguistic theory' in R Huxley \& E Ingram (eds) Language Acquisition: Models and Methods London: Academic Press. Pp.3-28.

Kasper G 1997 "A' stands for acquisition: A response to Firth and Wagner' The Modern Language Journal 81 (3):307-312.

Kasper G 2006 'Beyond repair: Conversation analysis as an approach to SLA' AILA Review 19:83-99

Kramsch C 1997 'The privilege of the nonative speaker' PMLA 112 (3):359-369.

Kramsch C 2000 'Second language acquisition applied linguistics and the teaching of foreign languages' The Modern Language Journal 84 (3):311-326.

Krashen S 1985 The Input Hypothesis: Issues and Implications London: Longman.

Lantolf JP 1994 'Sociocultural theory and second language learning: Introduction to the special issue' Modern Language Journal 78 (4):418-420.

Liddicoat A J 1997 'Interaction social structure and second language use: A response to Firth and Wagner' The Modern Language Journal 81 (3):313-317.

Long MH 1980 Input Interaction and Conversational Adjustments to Non-native Speakers PhD University of California Los Angeles.

Long MH 1996 'The role of the linguistic environment in second language acquisition' in WC Ritchie \& TK Bhatia (eds) Handbook of Second Language Acquisition San Diego: Academic Press. Pp.413-468.

Long MH 1997 'Construct validity in SLA research: A response to Firth and Wagner' The Modern Language Journal 81 (3):318-323.

Mehrabian A 1971 Silent Messages Belmont California: Wadsworth.

Montgomery C \& M Eisenstein 1985 'Real reality revisited - An experimental communicative course in ESL' TESOL Quarterly 19 (2): 317-334.

Nunan D 1987 'Communicative language teaching: Making it work' ELT Journal 41/2:136-45.

Paikeday T 1985 The Native Speaker is Dead! Toronto: Paikeday.

Pica T 1998 'Second language learning through interaction: Multiple perspectives' in V Regan (ed.) Contemporary Approaches to Second Language Acquisition in Social 
Contexts: Crosslinguistic Perspectives Dublin: University College Dublin Press.Pp. 931.

Poulisse N 1997 'Some words in defense of the psycholinguistic approach: A response to Firth and Wagner' The Modern Language Journal 81 (3):324-328.

Regan V 1998 'Introduction' in V Regan (ed.) Contemporary Approaches to Second Language Acquisition in Social Contexts: Crosslinguistic Perspectives Dublin: University College Dublin Press. Pp.1-8.

Savignon SJ 1987 'Communicative language teaching' Theory into Practice 26 (4):235-242.

Schegloff EA 1992 'Reflections on quantification in the study of conversation' Research on Language and Social Interaction 26:99-128.

Seedhouse P 1996 'Classroom interaction: Possibilities and impossibilities' ELT Journal 50 (1):16-24.

Seidlhofer B 2003 Controversies in Applied Linguistics Oxford: Oxford University Press.

Swain M 1993 'The output hypothesis: Just speaking and writing aren't enough' Canadian Modern Language Review 50:158-164.

VanPatten B 1982 .Why communication practices sometimes fail. Hispania 65 (3):403-407.

VanPatten B 1999 'What is second language acquisition and what is it doing in this department?' ADFL Bulletin 30 (3):49-53.

Varonis EM \& SM Gass 1985 'Miscommunication in native/nonnative conversation' Language in Society 14: 327-343.

Vygotsky L 1962 Thought and Language Cambridge MA: MIT Press.

Warren M 1993 Towards a Description of the Features of Naturalness in Conversation PhD University of Birmingham. 